Diagnosis

\section{Primary ciliary dyskinesia}

A Bush, C O'Callaghan

\section{A nose for a diagnosis?}

A ll children cough, all children have runny noses, and most children are normal. In a child with a cough, an unexpected additional finding, for example rectal prolapse, should lead to a reappraisal of what at first sight may be a trivial symptom, and a new diagnosis such as cystic fibrosis (CF) may be made. The well known frequency of this disease, the ready availability of the sweat test in every hospital and the generally low threshold for its performance, should make diagnosis of $\mathrm{CF}$ straightforward. However, even $\mathrm{CF}$, with all these favourable factors, is hardly a diagnostic success story; $10-15 \%$ patients are not diagnosed until adulthood. ${ }^{12}$ It is not surprising therefore that a rarer condition such as primary ciliary dyskinesia (PCD), to which the only diagnostic clues may be a chronic moist cough and a runny or blocked nose, and for which diagnostic testing is not widely available, is often missed for a long time. What is depressing is that even a very unexpected finding, mirror image organ arrangement, frequently does not prompt a diagnostic review for many years, ${ }^{3}$ long after the child has suffered lasting damage.

The incidence of PCD in the white population is estimated to be 1 in 15000 , although it is higher in communities where first cousin marriages are common. In the white population ${ }^{4}$ there will be around 70 new cases born per year, and it is estimated that there are 3000 cases in the UK in total. By contrast, only around 150 cases are known to the UK PCD support group (personal communication). Even if this group is aware of only one tenth of known cases, the implication is that there are large numbers of undiagnosed patients. Does this matter, and, if it does, how can this situation be rectified?

\section{FEATURES OF PCD}

Kartagener originally described a syndrome of mirror image organ arrangement (situs inversus), bronchiectasis, and sinusitis. ${ }^{5}$ The unexpected finding of electron microscopic abnormalities in the sperm tails from infertile men who had mirror image arrangement, ${ }^{6}$ led to the realisation that structural ciliary abnormalities underlie the condition.
Patients with similar clinical and cilial abnormalities, but without situs inversus, were later recognised, and together with patients with Kartagener's syndrome, they were classified as having immotile cilia syndrome. Immotile ciliary syndrome was renamed primary ciliary dyskinesia when functional studies of cilia from many of these patients showed them to have abnormal motility rather than being completely immotile.

A good history will enable the diagnosis of PCD to be suspected, provided that the possibility is considered. Typically, rhinitis or nasal congestion begins on the first day of life; it remains constant over time; and is difficult to treat. A number of infants have significant and unexpected respiratory distress at birth, necessitating admission to the special care baby unit. A persistent moist sounding cough within the neonatal period is unusual and suggestive. When diagnosis is late the history of early respiratory problems is often unclear, but rhinitis and/or nasal congestion and a moist sounding cough will have been an early and constant feature. Chronic secretory otitis media is very common ${ }^{7}$; if these children are subjected to tympanostomy tube insertion, a prolonged and offensive otorrhoea often results. The majority of males with PCD are infertile ${ }^{8}$ and females are at greater risk of ectopic pregnancy compared to unaffected women. Rarer associations of PCD include hydrocephalus ${ }^{9}$ secondary to abnormalities of brain ependymal cilia, complex congenital heart disease, oesophageal disease, ${ }^{10}$ and biliary atresia. ${ }^{11}$ The age related variation in presentation has been reviewed recently.

\section{DOES MISSING THE DIAGNOSIS MATTER?}

Does it matter if this diagnosis is missed? Intuitively it seems likely that early diagnosis followed by a programme of regular chest physiotherapy, exercise, and the aggressive use of antibiotics would be beneficial. In support of this view are the findings of Ellerman and colleagues. ${ }^{12}$ Lung function of patients at diagnosis, measured by forced expired volume in one second $\left(\mathrm{FEV}_{1}\right)$, was reduced by up to $50 \%$ in patients under 16 years and by up to $80 \%$ in those diagnosed in adulthood. While in the majority there was no improvement in lung function following diagnosis, institution of specialist respiratory management prevented further decline in lung function. This suggests that early diagnosis may prevent the development of bronchiectasis and the subsequent decline in lung function. The treatment of secretory otitis media is also different in PCD. A retrospective study showed that tympanostomy tube insertion prior to the diagnosis being established was common, fraught with complications, and had no beneficial effect on long term hearing. ${ }^{7}$ If hearing loss is sufficiently profound as to affect speech or learning at school, then using hearing aids for a short period, until spontaneous improvement occurs, is a better therapeutic option.

\section{ESTABLISHING THE DIAGNOSIS}

There are two tests that have been used to screen patients for referral. The saccharin test, which measures the time taken for a pellet of saccharin placed on the inferior turbinate to be tasted (normal $<30 \mathrm{~min}),{ }^{13}$ is very difficult to perform properly in children. Nasal nitric oxide (nNO) measurement looks more promising. It is typically very low in PCD $(<250 \mathrm{ppb}),{ }^{14}$ but also in some cases of $\mathrm{CF}$, severe rhinosinusitis of infective or allergic origin, and (in adults) diffuse panbronchiolitis. ${ }^{15}{ }^{16} \mathrm{~A}$ high nNO is thus a pointer against the diagnosis of $\mathrm{PCD}$, but a low nNO indicates the need for further testing.

Definitive testing requires referral to one of a very few centres. ${ }^{4}$ In the majority of cases it is better to send the child to the specialist centre for biopsy and diagnostic assessment. More recently a courier system has been set up where the referring paediatrician has been trained in the biopsy technique. Ciliary beat frequency can be measured using a variety of indirect techniques that rely on signals generated when moving areas of cilia interrupt the light passing to a photomultiplier or photodiode. ${ }^{4}$ Recorded values vary between methods and centres should have their own normal values across different age groups. More recently, with the advent of high speed digital video photography the precise beat pattern of respiratory cilia has been defined as has the beat pattern associated with different ultrastructural defects responsible for PCD. The high speed video technique, which can also measure beat frequency directly, has shown that approximately $10 \%$ of patients with PCD have a beat frequency within the normal range despite having a dyskinetic beat pattern. The implication from these findings is that if beat frequency analysis is used without beat pattern analysis and electron microscopy a significant number of false negative diagnoses will be made. 
Electron microscopy of cilia may confirm the diagnosis, although PCD with normal ultrastructure, sometimes with primary ciliary disorientation, is well described. ${ }^{17}{ }^{18} \mathrm{~A}$ key part of the diagnostic work up is to ensure that secondary ciliary disease (for example, changes caused by a viral infection) is not confused with PCD. ${ }^{19}$ If there is any doubt, repeat testing should be undertaken before the diagnosis is considered to be established. Great care is needed to prevent false positive and false negative diagnoses. In rare cases, where it is unclear whether the ciliary abnormalities are truly primary, culture of biopsy tissue may allow regrowth of cilia and definitive examination of beat frequency or motility. ${ }^{20}$ Its use is currently being assessed. Finally, in the future some families may be suitable for genetic testing. Cilia contain at least 200 separate proteins, so there are a huge number of potential candidate genes. ${ }^{21-23}$ It is therefore unlikely that genetic testing will be a useful diagnostic tool in the immediate future.

\section{PRACTICAL ISSUES-WHO SHOULD BE REFERRED?}

If we believe that the diagnosis of PCD is worth establishing, who should be referred for testing? Clearly it would be ridiculous to investigate every nursery school child with a runny nose and cough, so some degree of selectivity is needed. Unfortunately there are no evidence based guidelines to help us know who to refer. Referral for investigation is rarely a first line test for children with respiratory problems. However, we suggest the following should prompt the general paediatrician to consider referral for investigation ${ }^{4}$ :

- Neonatal onset of rhinitis and/or congestion, which has become continuous

- Neonatal respiratory distress in term infants with no obvious cause

- Patients with a history of a persistent wet sounding cough. In older patients there may just be a "wet click" associated with their cough. Almost all patients will have a history of rhinitis and/or nasal congestion. This may not be severe

- Situs inversus

- Prolonged otorrhoea after tympanostomy tube insertion

- A child with bronchiectasis without a definite cause

- Children with significant chest problems, without a firm diagnosis, refractory to asthma treatment

- Repeated courses of antibiotics for "chest infection"-no normal child has this requirement.

\section{FOLLOW UP}

We suggest that a shared care arrangement, analogous to that advocated for $\mathrm{CF}$, offers many advantages. All patients should have access to a specialist respiratory clinic and specialist ear, nose, and throat (ENT) advice. Ideally this would be in a specialist PCD clinic. Sputum or a cough swab should be cultured and spirometry, in those old enough, should be performed at each clinic visit. Audiometry, ENT expertise, and psychosocial support should also be available. Such a clinic should also be the source of much needed research into the basic mechanisms, genetics, and treatment of PCD. Recent Europe-wide initiatives to form a collaborative database of PCD are to be welcomed; surely future progress requires multicentre collaboration.

\section{CONCLUSION}

If the diagnosis of PCD is to be made and morbidity avoided, a clear, focused history and examination is required to select the child who needs specialist referral. At the moment, too many children with PCD are not being diagnosed early enough, and thus treated appropriately.

\section{Arch Dis Child 2002;87:363-365}

\section{Authors' affiliations}

A Bush, Department of Paediatric Respiratory Medicine, Royal Brompton Hospital, Sydney Street, London, UK

C O'Callaghan, Department of Child Health, University of Leicester, Leicester, LE2 7LX, UK

Correspondence to: $\operatorname{Dr}$ A Bush, Department of Paediatric Respiratory Medicine, Royal Brompton Hospital, Sydney Street, London SW3 6NP, UK; a.bush@rbh.nthames.nhs.uk

\section{REFERENCES}

1 Cystic Fibrosis Foundation. Patient Registry 1996 Annual Data Report. Bethesda, Maryland, August 1997.

2 Gan K-H, Geus WP, Bakker W, et al. Genetic and clinical features of patients with cystic fibrosis diagnosed after the age of 16 years. Thorax 1995;50:1301-4.

3 Coren MF, Meeks M, Buchdahl RM, et al. Primary ciliary dyskinesia (PCD) in children: age at diagnosis and symptom history. Acta Pediatr. In press.

4 Bush A, Cole P, Hariri $M$, et al. Primary ciliary dyskinesia: diagnosis and standards of care. Eur Respir J 1998;12:982-8.

5 Kartagener $M$. Zur pathogenese der bronkiectasian bei situs viscerum inversus. Britrage zur Klinik and Erforshung der Tuberkulose und der lungen krankheiten 1933;83:489-501.

6 Afzelius BA. A human syndrome caused by immotile cilia. Science 1976;193:317-19.

7 Hadfield PJ, Rowe-Jones JM, Bush A, et al. Treatment of otitis media with effusion in children with primary ciliary dyskinesia. Clin Otolaryngol 1997;22:302-6.

8 Munro NC, Currie DC, Lindsay KS, et al. Fertility in males with primary ciliary dyskinesia presenting with respiratory infection. Thorax 1994;49:684-7.

9 Greenstone MA, Jones RWA, Dewar A, et al. Hydrocephalus and primary ciliary dyskinesia. Arch Dis Child 1984;59:481-2.
10 Gemou-Engesaeth V, Warner JO, Bush A. New associations of primary ciliary dyskinesia syndrome. Pediatr Pulmonol 1993;16:9-12.

11 Baruch GR, Gotffried E, Pery M, et al. Immotile cilia syndrome including polysplenia, situs inversus and extrahepatic biliary atresia. Am J Med Genet 1989;33:390-3.

12 Ellerman A, Bisgaard $\mathrm{H}$. Longitudinal study of lung function in a cohort of primary ciliary dyskinesia. Eur Respir J 1997;10:2376-9.

13 Stanley P, MacWilliam L, Greenstone M, et al. Efficacy of a saccharin test for screening to detect abnormal mucociliary clearance. Br J Dis Chest 1984;78:62-5.

14 Karadag B, James AJ, Gultekin E, et al. Nasal and lower airway level of nitric oxide in children with primary ciliary dyskinesia. Eur Respir J 1999;13:1402-6.

15 Balfour-Lynn IM, Laverty A, Dinwiddie R. Reduced upper airway nitric oxide in cystic fibrosis. Arch Dis Child 1996;75:319-22.

16 Nakano H, Ide H, Imada M, et al. Reduced nasal nitric oxide in diffuse panbronchiolitis. Am J Respir Crit Care Med 2000;162:2218-20.

17 Rutman A, Cullinan P, Woodhead M, et al. Ciliary disorientation: a possible variant of primary ciliary dyskinesia. Thorax 1993;48:770-1.

18 Biggart E, Pritchard K, Wilson R, et al. Primary ciliary dyskinesia syndrome associated with abnormal ciliary orientation in infants. Eur Respir J 2001;17:444-8.

19 Cornillie FJ, Lauweryns JM. Atypical bronchial cilia in children with recurrent respiratory tract infections. Pathol Res Pract 1984; 178:595-604.

20 Jorissen M, Bessems A. Normal ciliary beat frequency after ciliogenesis in nasal epithelial cells cultured sequentially as monolayer and in suspension. Acta Otolaryngol 1995; 115:66-70.

21 Dutcher KS. Flagellar assembly in two hundred and fifty easy to follow steps. Trends Genet 1995:11:398-404.

22 Meeks M, Waine A, Spiden S, et al. A locus for primary ciliary dyskinesia maps to chromosome 19q. J Med Genet 2000;37:241-4.

23 Blouin J-L, Meeks M, Radhakrishna U, et al. Primary ciliary dyskinesia: a genome wide linkage analysis reveals extensive locus heterogeneity. Eur J Hum Genet

2000;8: 109-18.

\section{COMMENTARY}

\section{THE DISTRICT HOSPITAL} PERSPECTIVE

One of the most difficult tasks facing the general paediatrician is the identification of a significant medical disorder from the large number of children presenting with an otherwise common and benign problem. Examples of this include diagnosing intracranial tumours in children with headaches, identifying which children with a petechial rash have meningococcal septicaemia, and screening out children with prolonged jaundice who have biliary atresia. It is always very much easier from the perspective of a tertiary centre with the benefit of hindsight to see where diagnoses have been missed and to draw up recommendations for the diagnosis and screening of rare disorders presenting with common symptoms. However, these guidelines may be impractical for the referring paediatrician.

Primary ciliary dyskinesia falls very much into this category. It has an 
incidence of between 1 in 15000 and 1 in $20000^{12}$ - that is, an incidence of one tenth of that of cystic fibrosis. The main clinical features of PCD are a cough, rhinitis, unexplained neonatal respiratory distress, and situs inversus. ${ }^{3}$

All children develop colds and most of them will also cough from time to time. Even the symptom of a chronic cough is a very common finding: $10 \%$ of $8-11$ year old children have a nocturnal cough ${ }^{4}$; $13 \%$ of children cough most days for three months of the year"; and, interestingly, there seems to be a higher incidence of chronic cough in children from higher socioeconomic groups. ${ }^{6}$ Cough medications are among the most widely used remedies throughout the world. ${ }^{7}$ To make matters even more difficult for the general paediatrician, the reporting of childhood cough has poor repeatability and is very subjective. ${ }^{89}$

Serous otitis media (glue ear) is also very common, affecting $15-20 \%$ of children aged $1-5$ years at any time. ${ }^{10}$ Recurrent otitis media, defined as three bouts of otitis media in six months, ${ }^{11}$ undoubtedly occurs more frequently in PCD, but it also has an increased incidence with a positive family history, submucous cleft palate, nursery care, allergy, chronic sinusitis, immune deficiency, and nasopharyngeal tumour. ${ }^{12}$

It is difficult to estimate with accuracy the incidence of unexplained respiratory distress at term. It seems probable that many children labelled with transient tachypnoea of the newborn, aspiration, or surfactant deficiency respiratory distress may in fact have undiagnosed respiratory distress.

How then is the hard pressed general paediatrician to ensure that he or she does not miss the one or two cases of PCD that present during the course of a career in paediatrics? An accurate history and thorough examination may be a pointer towards the diagnosis of PCD, particularly if the child is failing to thrive or coughing up mucopurulent sputum. Situs inversus should certainly alert the paediatrician to the diagnosis of PCD and there is a strong argument to investigate every child with dextrocardia, particularly if there are any respiratory symptoms. However, a chronic cough, rhinitis, and serous otitis media are all so common that it is impractical and prohibitively expensive to refer every such child for investigation of PCD. Although a low nasal nitric oxide ${ }^{13}$ and a negative saccharin test in older children ${ }^{14}$ may point towards the diagnosis of PCD, these investigations are unreliable and not widely available. The definitive diagnosis relies on a brush biopsy, ${ }^{35}$ which is available in very few centres in the UK. It seems probable that if every child with severe rhinitis, unexplained neonatal respiratory distress, a productive cough, and troublesome otitis media were referred for brush biopsy, this would completely overwhelm the presently available facilities. Until a cheap, reliable screening test, comparable to the sweat test or DNA testing is available, cases of PCD will continue to be diagnosed late.

A Boon

Department of Paediatrics, Royal Berkshire Hospital, Reading, UK; andrew.boon@rbbh-tr.nhs.uk

\section{REFERENCES}

1 Rott H-D. Genetics of Kartagener's syndrome. Eur J Respir Dis 1983;(suppl 127): 1-4.
2 Meeks M Bush A. Primary ciliary dyskinesia (PCD). Pediatr Pulmonol 2000;29:307-16.

3 Bush A, Cole P, Hariri M, et al. Primary ciliary dyskinesia: diagnosis and standards of care. Eur Respir J 1998;12:982-8.

4 Gray EJ, Peat, JK, Mellis CM, et al. Asthma severity and morbidity in a population sample of Sydney schoolchildren. Part I-Prevalence and effect of air pollutants in coastal regions. Aust N Z J Med 1994;24:168-75.

5 Cuijpers CE, Wesseling GJ, Swaen GM, et al. Asthma-related symptoms and lung function in primary school children. J Asthma 1994:31:301-12.

6 Faniran AO, Peat JK, Woolcock AJ. Measuring persistent cough in children in epidemiological studies: development of a questionnaire and assessment of prevalence in two countries. Chest 1999;1 15:434-9.

7 Kogan MD, Pappas G, Yu SM, et al. Over-the-counter medication use among preschool-age children. JAMA 1994;272: 1025-30.

8 Archer LNJ, Simpson H. Night cough counts and diary card scores in asthma. Arch Dis Child 1985;60:473-4.

9 Chang $\mathbf{A B}$, Newman RG, Carlin J, et al. Subjective scoring of cough in children: parent-completed vs child-completed diary cards vs an objective method. Eur Respir J 1998;11:462-6.

10 Zielhuis GA, Rach GH, Bosch AV, et al. The prevalence of otitis media with effusion: a critical review of the literature. Clin Otolaryngol 1990;15:283-8.

11 Klein JO. Antimicrobial prophylaxis for recurrent acute otitis media. Pediatr Ann 1984; 13:398-403.

12 Jung TTK, Hanson JB. Classification of otitis media and surgical principles. Otolarngol Clin N Am 1999;32:369-83.

13 Karadag B, James AJ, Gultekin E, et al. Nasal and lower airway level of nitric oxide in children with primary ciliary dyskinesia. Eur Respir J 1999;13:1402-6.

14 Stanley P, MacWilliam L, Greenstone M, et al. Efficacy of a saccharine test for screening to detect abnormal mucociliary clearance. $\mathrm{Br} J$ Dis Chest 1984;78:62-5.

15 de longh RU, Rutland J. Ciliary defects in healthy subjects, bronchiectasis and primary ciliary dyskinesia. Am J Respir Crit Care Med 1995; 151:1559-67. 